\title{
EFEITOS DA PRESENÇA HUMANA SOBRE AS INTERAÇÕES SOCIAIS DE MACACOS-PREGOS-GALEGOS [SAPAJUS FLAVIUS) EM CATIVEIRO
}

\author{
INPUTS FROM THE HUMAN INTERACTION IN BLOND CAPUCHNN (SAPAJUS FLAVIUS] IN CAPTIVITY
}

\author{
Gibran Anderson Oliveira da Silva ${ }^{1}$ \\ Natan Diego Alves Freitas ${ }^{2}$ \\ Pedro Emmílio de Lima Marinho ${ }^{3}$ \\ Eudécio Carvalho $\mathrm{Neco}^{4}$ \\ Tainá Sherlakyann Alves Pessoa ${ }^{5}$ \\ Bráulio Almeida Santos ${ }^{6}$
}

\section{Resumo}

Sapajus flavius ou macaco-prego-galego foi redescoberta em 2006 e se encontra em Perigo de Extinção. Os parques zoológicos atuam na educação ambiental, conservação, manutenção e reprodução desses animais em cativeiro. Contudo, quais são os efeitos da presença humana sobre os macacos-pregos-galegos em cativeiro? Este trabalho objetivou descrever e analisar as interações sociais das classes sexoetárias de um grupo ex situ de S. flavius, de acordo com a presença e ausência de visitantes em um contexto de oferta alimentar no Parque Zoobotânico Arruda Câmara na Paraíba. Para isso, foram adaptados métodos desenvolvidos com populações de macaco-prego-galego in situ. Os comportamentos mais frequentes obtidos foram Vocalização(36,28\%), Monopolização(14,46\%), Estereotipia(13,16\%) e Agonismo Antrópico(11,3\%). O comportamento de Esfregar a Barbela não ocorreu durante a coleta de dados, podendo indicar um possível aspecto cultural sobre tal interação e/ ou alteração causada pelo cativeiro e pelas perturbações humanas. Na presença de visitantes as interações "Agonistas" ( $\mathrm{p}<\mathrm{0.01}$ ) e o "Repouso" ( $\mathrm{p}<0.05)$ diminuíram de modo significativo. Enquanto que o "Agonismo Antrópico" ( $p<0.01)$ aumentou significativamente com a presença dos visitantes. Portanto, os macacos-pregosgalegos cativos sofreram alterações das interações sociais pelo estresse do cativeiro e também por perturbações causadas pela presença humana.

1 Departamento de Sistemática e Ecologia da Universidade Federal da Paraíba. Laboratório de Ecologia Aplicada à Conservação da UFPB. Laboratório de Mamíferos da UFPB. https://orcid.org/oooo-ooo1$8451-2123$

2 Departamento de Sistemática e Ecologia da Universidade Federal da Paraíba. Laboratório de Mamíferos da UFPB. https://orcid.org/oooo-0oo2-0858-3269

3 Departamento de Sistemática e Ecologia da Universidade Federal da Paraíba. Laboratório de Estudos em Memória e Cognição da UFPB. https://orcid.org/oooo-0oo3-4093-2323

4 Departamento de Sistemática e Ecologia da Universidade Federal da Paraíba. Laboratório de Ecologia Aplicada à Conservação da UFPB. https://orcid.org/oooo-ooo1-7557-869X

5 Departamento de Sistemática e Ecologia da Universidade Federal da Paraíba. Laboratório de Ecologia Aplicada à Conservação da UFPB. https://orcid.org/oooo-0oo3-1516-7412

6 Departamento de Sistemática e Ecologia da Universidade Federal da Paraíba. Laboratório de Ecologia Aplicada à Conservação da UFPB. http://orcid.org/oooo-ooo1-6046-4024 
Palavras-chave: Sapajus flavius; Comportamento; Cativeiro.

\begin{abstract}
Sapajus flavius or blonde-capuchin-monkey, rediscovered in 2006, is Endangered of Extinction. Zoos act in the environmental education, conservation, maintenance and reproduction of these animals in captivity. However, what are the effects of human presence on captive blonde-capuchin-monkeys? This work aimed to describe and analyze the social interactions of the sex-age classes of an ex situ group of $S$. flavius according to the presence and absence of visitors in a food supply context in the Zoobotanical Park Arruda Câmara in Paraíba. Methods developed with populations of macaco-prego-gallego in situ were adapted. The most frequent behaviors were Vocalization (36.28\%), Monopolization (14.46\%), Stereotypy (13.16\%) and Anthropic Agonism (11.3\%). The behavior of "Rub the Barbella" did not occur during data collection and may indicate a possible cultural aspect about such interaction and / or alteration caused by captivity and human disturbances. In the presence of visitors the interactions "Agonists" ( $\mathrm{p}<0.01$ ) and "Rest" ( $\mathrm{p}<0.05$ ) decreased significantly. While "Anthropic Agonism" ( $\mathrm{p}<\mathrm{o.01}$ ) increased significantly with the presence of visitors. Thus, the captive-capuchin monkeys have undergone changes in social interactions due to the stress of captivity and also to disturbances caused by human presence.
\end{abstract}

Keywords: Sapajus flavius; Behavior; Captivity.

\title{
INTRODUÇÃO
}

O macaco-prego-galego (Sapajus flavius) é uma espécie endêmica do Centro de Endemismo Pernambuco no Nordeste brasileiro, redescoberta em 2006. Atualmente os impactos antrópicos sobre os macacos-pregos-galegos são intensos, a espécie está "Em Perigo de Extinção" na Lista Nacional Oficial de Espécies da Fauna Ameaçadas de Extinção (MMA, 2014) e criticamente ameaçada de extinção (CR) na lista vermelha da International Union for Conservation of Nature (IUCN, 2015). Por isso, para preservação e conservação a curto e longo prazo $S$. flavius está incluída no Plano de Ação Nacional para Conservação dos Primatas do Nordeste (PAN PriNE) (ICMBio, 2012).

A dieta do gênero Sapajus é onívora, principalmente frugívoro-insetívoro. Os itens da dieta podem ser incrementados de acordo com as atividades humanas próximas às áreas de vida e pela preferência e o oportunismo das próprias populações de $S$. flavius, como a cana-de-açúcar, milho e mandioca. Além de vertebrados, como lagartos e marsupiais (Santos, 2010;2013; Rodrigues, 2013b; Valença-Montenegro, 2011; Neco, 2015; Silva; Valença-Montenegro, 2016). Portanto, é evidente a flexibilidade comportamental da espécie para ocupação de vários habitats, inclusive dos antromas onde as fontes alimentares são provenientes de cultivos agrícolas (Fragaszy et al, 2004; Ludwig et al, 2005; Neco, 2015; Silva; Valença-Montenegro, 2016). 
As interações sociais desses animais indicam uma possível hierarquia de acordo com as classes-etárias e o sexos dos indivíduos de grupos de macacos-pregosgalegos selvagens. As interações agonísticas atuam como uma forma de intimidação ou ameaça em contextos de conflitos entre os animais, esse comportamento pode estar associado com a disputa por recursos alimentares e pares sexuais, como também pela hierarquia do grupo (Strier, 2003; Santos, 2013a; Neco, 2015). Dependendo do tamanho populacional, das condições e dos recursos disponíveis outros tipos de interações podem ocorrer, como as interações harmônicas intraespecíficas expressas em comportamentos afiliativos, como a catação, que representam comportamentos positivos de um indivíduo em relação ao outro (Izar, 2009; Valença-Montenegro, 2011).

A estrutura e a interação social de $S$. flavius in situ relatam a persistência do acasalamento multi-macho e multi-fêmea, e comportamentos afiliativos frequentes, além de uma baixa quantidade de interações agonísticas, como agressão direta. Vários tipos de vocalizações dos indivíduos podem indicar também interações comportamentais tanto agonísticas quanto afiliativas (Valença-Montenegro, 2011; Bezerra et al, 2014; Neco, 2015). Membros dominantes das populações podem ser classificados de acordo com as interações exercida, como o acesso prioritário aos recursos alimentares e aos parceiros sexuais (Fragaszy et al, 2004; Suscke, 2009; Izar, 2009). Neco (2015) ainda relata comportamentos de marcação peculiares de S. flavius, como a esfregação da barbela sobre substratos, possivelmente relacionado com uma comunicação química e hierarquia social, embora estudos ainda sejam necessários para afirmar a funcionalidade e a origem desse comportamento.

Atualmente os parques zoológicos são ferramentas fundamentais para promoção de entretenimento, educação, extensão, pesquisa e conservação de espécies ameaçadas de extinção (Tribe; Booth, 2003; Neves, 2018). Porém, deve-se considerar o contexto dos animais cativos, como o aumento do estresse e a presença de comportamentos distintos de animais no ambiente natural. Estes efeitos podem ser gerados pela presença humana e pelo próprio viveiro, possivelmente, ocasionando a diminuição da qualidade de vida do grupo e inviabilizando reintrodução in situ de indivíduos a partir das espécimes cativas (Hare, 2000; Saatchi, 2001; Jacobsen et al, 2010).

Quais são os efeitos da presença humana sobre os comportamentos sociais e alimentares de um grupo de macacos-pregos-galegos em cativeiro? Nessa pesquisa, nós descrevemos e analisamos os comportamentos sociais entre as classes etárias e o sexos de Sapajus flavius ex situ em um contexto de oferta alimentar de acordo com a presença e ausência de visitantes. A pesquisa visa contribuir com informações sobre as interações sociais da espécie em cativeiro e avaliar o recinto e as demais técnicas de manejo aplicadas à $S$. flavius em cativeiro, possibilitando auxiliar em estratégias de conservação e manejo que melhorem a qualidade de vida da espécie ex situ, tanto para educação e enriquecimento ambiental quanto para reabilitação de animais para reintrodução. Além de verificar o efeito das intervenções antrópicas, como visitações. 


\section{MATERIAL E MÉTODOS}

\section{Área de Estudo}

O Parque Zoobotânico Arruda Câmara foi fundado em 26 de agosto de 1980, possui uma área de 26,8 ha e é um dos pontos turísticos mais visitados da cidade de João Pessoa, capital da Paraíba. O zoológico está cercado pelo centro da cidade e atua como um fragmento de Floresta Atlântica fundamental para a biodiversidade local (Fig. 1). O parque é administrado pela prefeitura da cidade e possui quinhentos animais de oitenta espécies cativos, além de outras espécies in situ.

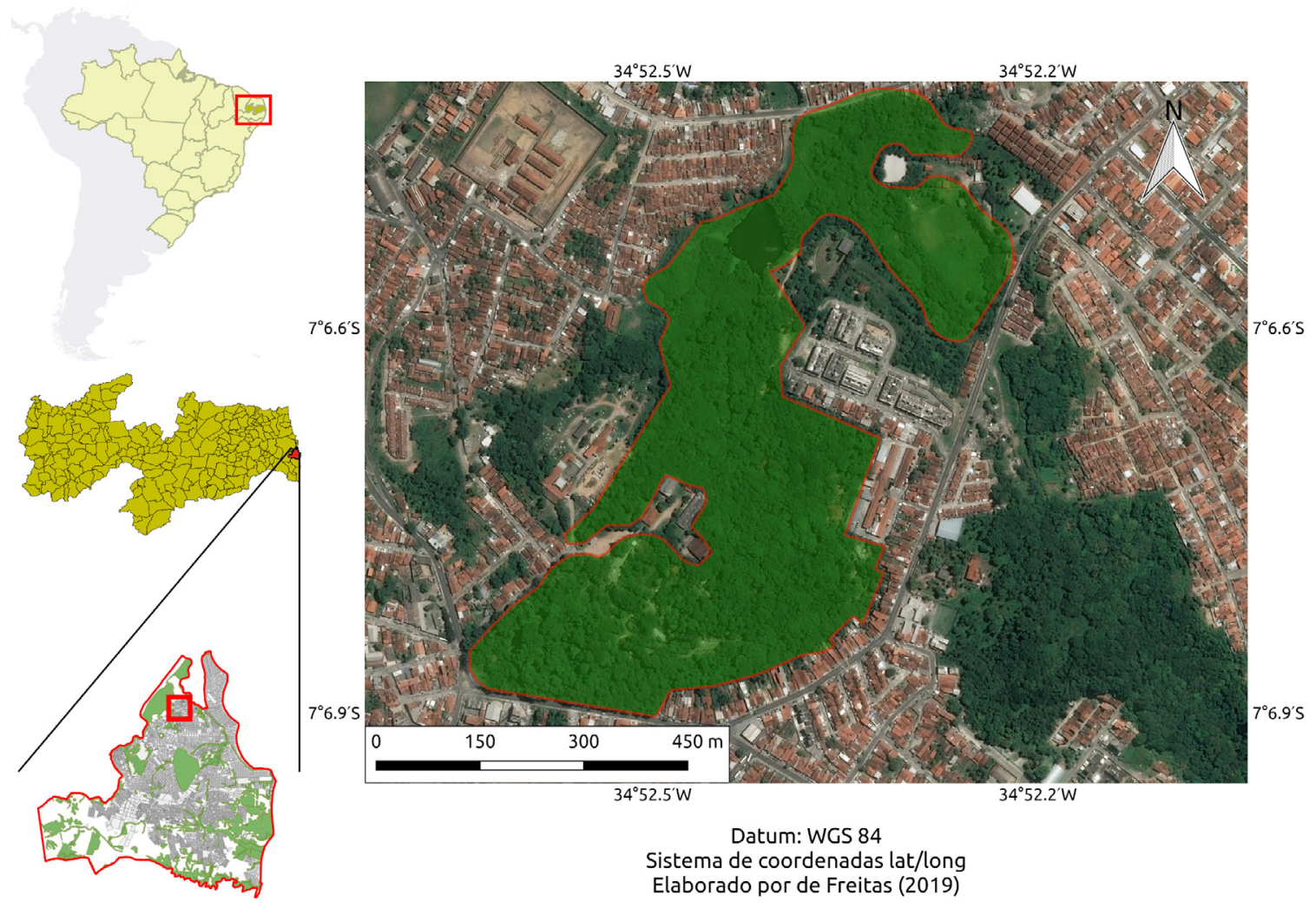

Figura 1. Localização do Parque Arruda Câmara no município de João Pessoa, Paraíba.

\section{Esforço amostral}

Durante o mês de novembro de 2016, foram realizadas quatro visitas ao parque, duas em dias fechados aos visitantes e duas em dias abertos aos visitantes. As análises iniciaram pela manhã no horário de alimentação dos macacos-pregosgalegos, aproximadamente às 8 horas com término entorno das 11 horas da manhã; totalizando 16 horas de amostragem. 


\section{Grupo de estudo}

Antes da coleta de dados deste estudo ocorreu o falecimento recente do indivíduo mais velho do recinto, um macho-adulto. O grupo de estudo no início das observações era composto por seis indivíduos, sendo que no segundo dia de análise deste trabalho um filhote nasceu, passando assim a composição de sete indivíduos. Estes fatos provavelmente devem ter alterado a estrutura social do grupo. De acordo com a classificação sexo-etária os indivíduos estão distribuídos em: dois machos adultos; um macho sub-adulto; duas fêmeas adultas; um jovem; e um infante.

\section{Recinto}

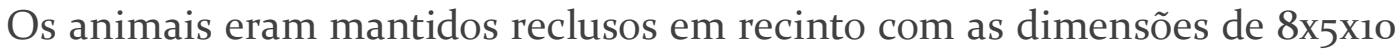
metros aproximadamente, o cativeiro também possuía enriquecimento ambiental com troncos, caules de bambu, com tanque com água e cordas que eram bastante utilizados pelos animais desde o deslocamento até para perseguições, interações afiliativas e agonísticas. Os indivíduos eram mantidos à disposição da visitação de terça-feira aos domingos, de forma que a distância entre o limite da grade e a passarela dos visitantes é de aproximadamente um metro.

\section{Alimentação no recinto}

Os animais recebiam comida uma vez por dia, geralmente entre as 7 e 8 horas da manhã. A composição da dieta era majoritariamente composta por vegetais, como: melão; banana; maçã; mamão; melancia; laranja; pepino e ração. Para a distribuição do alimento no ambiente, os tratadores abriam a grade do lado anterior do recinto e ofertavam os alimentos. É neste momento também que ocorria a limpeza do recinto com recolhimento de dejetos e restos de comida do dia anterior.

\section{Caixa de Alimentos}

Os procedimentos realizados neste trabalho foram adaptados da pesquisa de Neco (2015). Para gerar um contexto de controle dos comportamentos alimentares dos animais e verificar a frequência dos alimentos consumidos durante as sessões. Foram utilizados os itens alimentares disponibilizados pelos zootecnistas que produzem a dieta do grupo, a fim de evitar déficits nutricionais aos animais. Foram depositados diferentes tipos de alimentos em cada compartimento interno e fotos foram registradas no início e fim de cada sessão de coleta de dados (Fig. 4). 
A caixa de alimentos era fechada e introduzida no recinto por intermédio dos tratadores e dos pesquisadores, com os alimentos separados nos compartimentos (Fig. 2 e 4). A caixa era posicionada sempre no mesmo local durante as sessões, no chão e meio do recinto para aproximar os indivíduos durante o acesso aos alimentos. Desse modo, é possível verificar a existência de padrões de predominância de acesso aos recursos e também se a alimentação dos animais sofria efeitos da presença e ausência de visitantes (Pinha, 2007; Neco, 2015). A coleta de dados iniciavam quando o primeiro animal alcançava a caixa (Fig. 3).

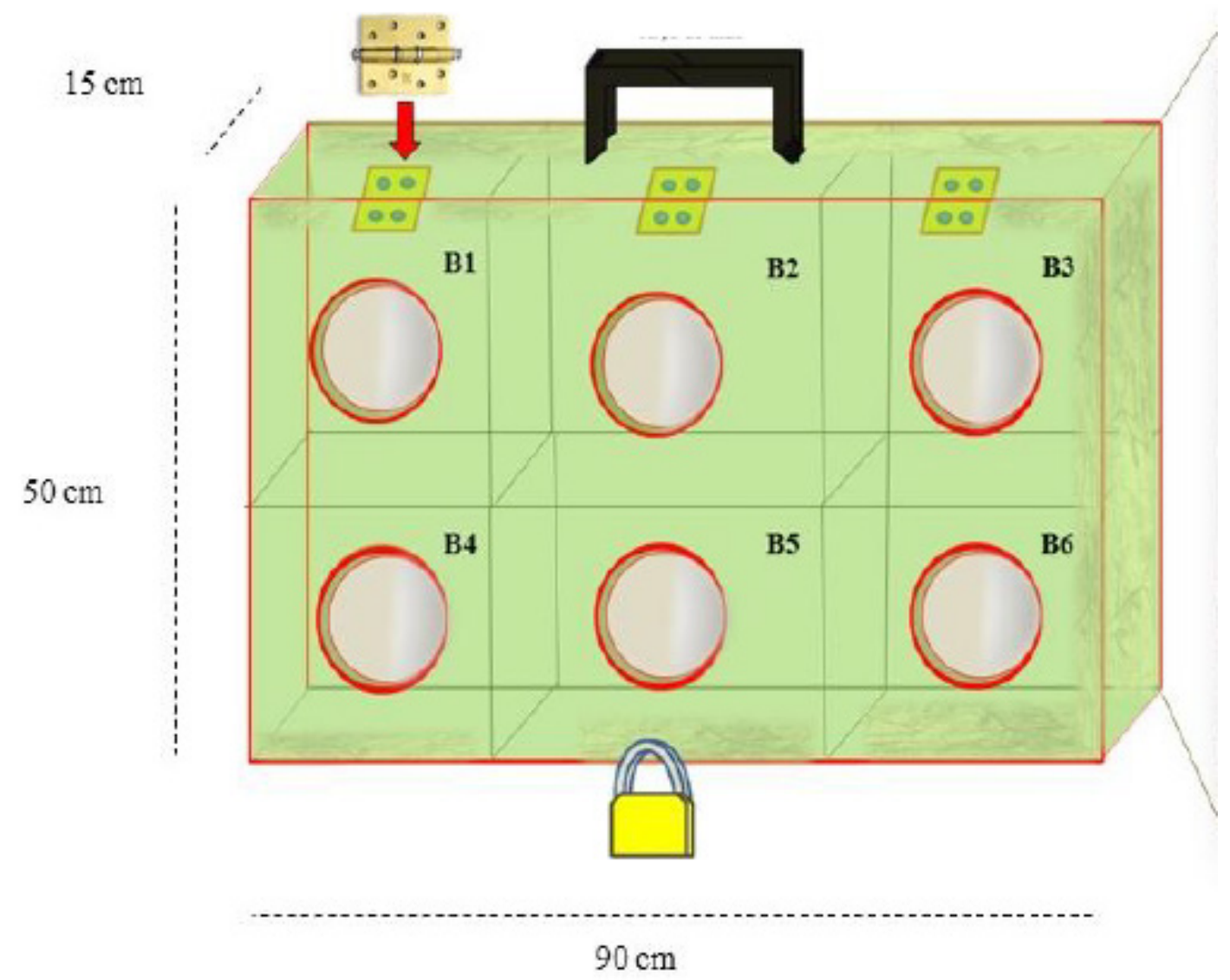

Figura 2. Caixa de alimentos utilizada em sessão de competição induzida. Fonte: Neco, 2015 .

\section{Coleta de dados comportamentais}

A metodologia "todas as ocorrências" foi utilizada para registrar os comportamentos sociais através de um etograma baseado na pesquisa de Neco (2015) com três categorias de interações: afiliativas; agonísticas; e outros, além de anotações Ad libitum (Altmann, 1974; Neco, 2015; Silva, 2016). Os comportamentos foram observados pelos pesquisadores a uma distância de aproximadamente um metro, na passarela dos visitantes, de frente ao recinto. 
Entretanto, tendo em vista que populações de animais ex situ possuem interações distintas de populações em seus habitats naturais, dois comportamentos foram adicionados ao etograma. Esses comportamentos foram adicionados a categoria "outros": estereotipia e agonismo antrópico; este último indicando comportamentos de ameaça direcionada aos pesquisadores, visitantes ou funcionários que transitavam próximo ao recinto (Tab. 1).

Dentro da categoria agonista estavam distribuídos os comportamentos: Afastar (AF); Agredir (AG); Ameaçar (AM) e Perseguir (PE). Já para as interações afiliativas: Brincar (BR); Catação (CA); Aliança (AL); Repouso (RE) e Doação (DO). A categoria outros incluem interações que não são se conhece a funcionalidade, foram classificados esses comportamentos em: Esfregar barbela (EB); Vocalização (VO); Solicitar (ME); Monopolizar (MO); Estereotipia (ES); Agonismo antrópico (AA) e Surrupiar (SU) .

\section{Análise de dados}

Foram observados e registrados os itens presentes na caixa de alimentos em cada compartimento antes e após o fim das sessões de competição induzida. Para verificar a quantidade de vezes que determinado comportamento ocorreu dentro da população ex situ de $S$. flavius foi calculada a frequência relativa para cada tipo de interação e também para os comportamentos específicos.

Foram testadas as hipóteses de diferenças de frequências em comportamentos durante a presença e ausência de visitantes. Esperava-se que os comportamentos: Agonismo antrópico (AA), Monopolizar (MO); Estereotipia (ES); Vocalização (VO) aumentariam e Repousar (RE) diminuiria no período com visitantes. Além disso, foi testada a diferença de frequência para as categorias comportamentais agonística, afiliativa e outros. O esperado é que os comportamentos agonísticos e outros iriam aumentar enquanto os afiliativos iriam diminuir. Para isso, foi utilizado Modelos Aditivos Generalizados (GAM) utilizando uma distribuição binomial para variável visitação (presença/ausência) por meio do software R (R Core Team, 2019). 
Tabela 1. Categorias comportamentais (adaptado de Rodrigues, 2013a; Santos, 2013; Neco, 2015)

\begin{tabular}{|c|c|c|}
\hline Categoria & Código & Descrição \\
\hline Afastar & $\mathrm{AF}$ & $\begin{array}{l}\text { Afastar ou empurrar outro indivíduo disputando pelo espaço } \\
\text { ou recurso. }\end{array}$ \\
\hline Agredir & AG & $\begin{array}{l}\text { Puxar, bater e/ou causar danos físicos que comprometa a } \\
\text { integridade de outros animais. }\end{array}$ \\
\hline Ameaçar & $\mathrm{AM}$ & $\begin{array}{l}\text { Demonstrar os dentes, piloereção, se balançar ou se mover } \\
\text { subitamente em direção a outro indivíduo. }\end{array}$ \\
\hline Perseguir & PE & $\begin{array}{l}\text { Se locomover de forma hostil em direção a outro outro animal } \\
\text { percorrendo o espaço físico com certa duração de tempo. }\end{array}$ \\
\hline Brincar & BR & $\begin{array}{l}\text { Interagir com outros indivíduos ou objetos de forma recreativa } \\
\text { e amistosa exibindo expressões faciais ou se movimentando, } \\
\text { puxando a cauda e rolando. }\end{array}$ \\
\hline Catação & CA & $\begin{array}{l}\text { Retirar ectoparasitas ou detritos presos na pelagem de outros } \\
\text { indivíduos, eventualmente, utilizando as mãos ou a boca } \\
\text { para a remoção. }\end{array}$ \\
\hline Aliança & AL & $\begin{array}{l}\text { Agregação com outro indivíduo, seja subindo no dorso ou } \\
\text { apoiando o braço, mostrando os dentes, se locomovendo e } \\
\text { vocalizando para ameaçar um terceiro. }\end{array}$ \\
\hline Repousar & $\mathrm{RE}$ & $\begin{array}{l}\text { Descansar deitados ou se apoiar no tronco sem se movimentar } \\
\text { em posição de relaxamento. }\end{array}$ \\
\hline Doação & DO & $\begin{array}{l}\text { Compartilhamento de alimento entregando partes do recurso } \\
\text { com a mão ou com a boca para outro indivíduo. }\end{array}$ \\
\hline Esfregar barbela & EB & $\begin{array}{l}\text { Friccionar o pescoço/barbela contra o substrato, iniciando } \\
\text { pelo nariz e pela boca, coçando e esfregando a região esternal } \\
\text { e, eventualmente, lambendo a secreção expelida no local. }\end{array}$ \\
\hline Vocalizar & $\mathrm{VO}$ & $\begin{array}{l}\text { Quando um ou mais indivíduos emitem vocalização, } \\
\text { aparentemente, associada à interação social. }\end{array}$ \\
\hline Solicitar & ME & $\begin{array}{l}\text { Aproximara boca ou estendera palma da mão se aproximando } \\
\text { de outro indivíduo vocalizando de forma aguda solicitando } \\
\text { alimento. }\end{array}$ \\
\hline Monopolizar & $\mathrm{MO}$ & $\begin{array}{l}\text { Quando um indivíduo se alimenta sobre a caixa do } \\
\text { experimento ou segurando um recurso e não permite que } \\
\text { outros se aproximem. }\end{array}$ \\
\hline Estereotipia & ES & $\begin{array}{l}\text { Comportamentos repetitivos e alheios da realidade, como } \\
\text { rodopiar e levantar a cabeça. }\end{array}$ \\
\hline Agonismo Antrópico & AA & $\begin{array}{l}\text { Ameaça ou vocalização agonística direcionada aos seres } \\
\text { humanos. }\end{array}$ \\
\hline Surrupiar & SU & $\begin{array}{l}\text { Obter apenas as sobras de alimento de outro indivíduo de } \\
\text { modo repentino, se escondendo após a captura da sobra. }\end{array}$ \\
\hline
\end{tabular}




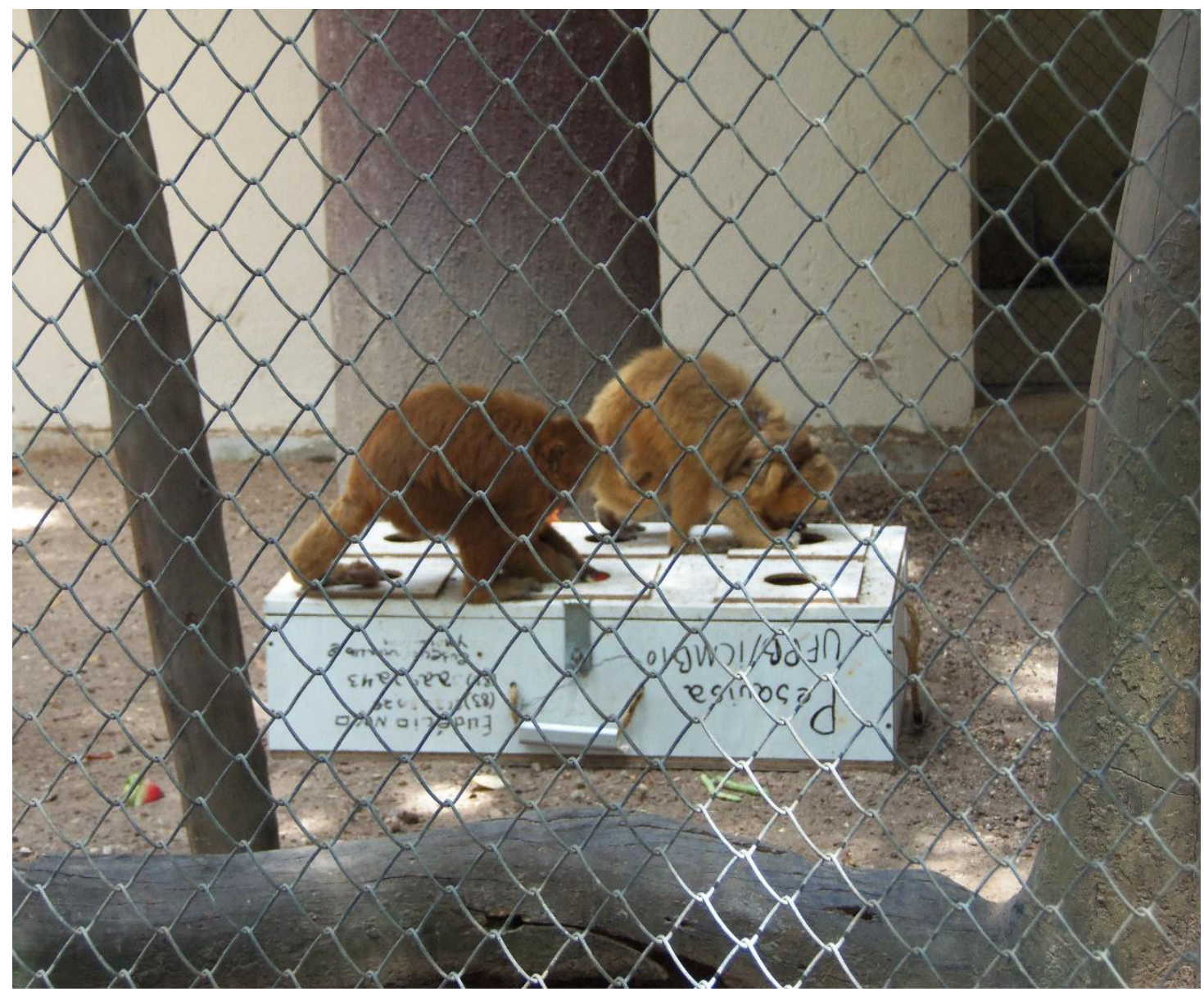

Figura 3. Caixa de alimentos introduzida ao chão e no centro do recinto.
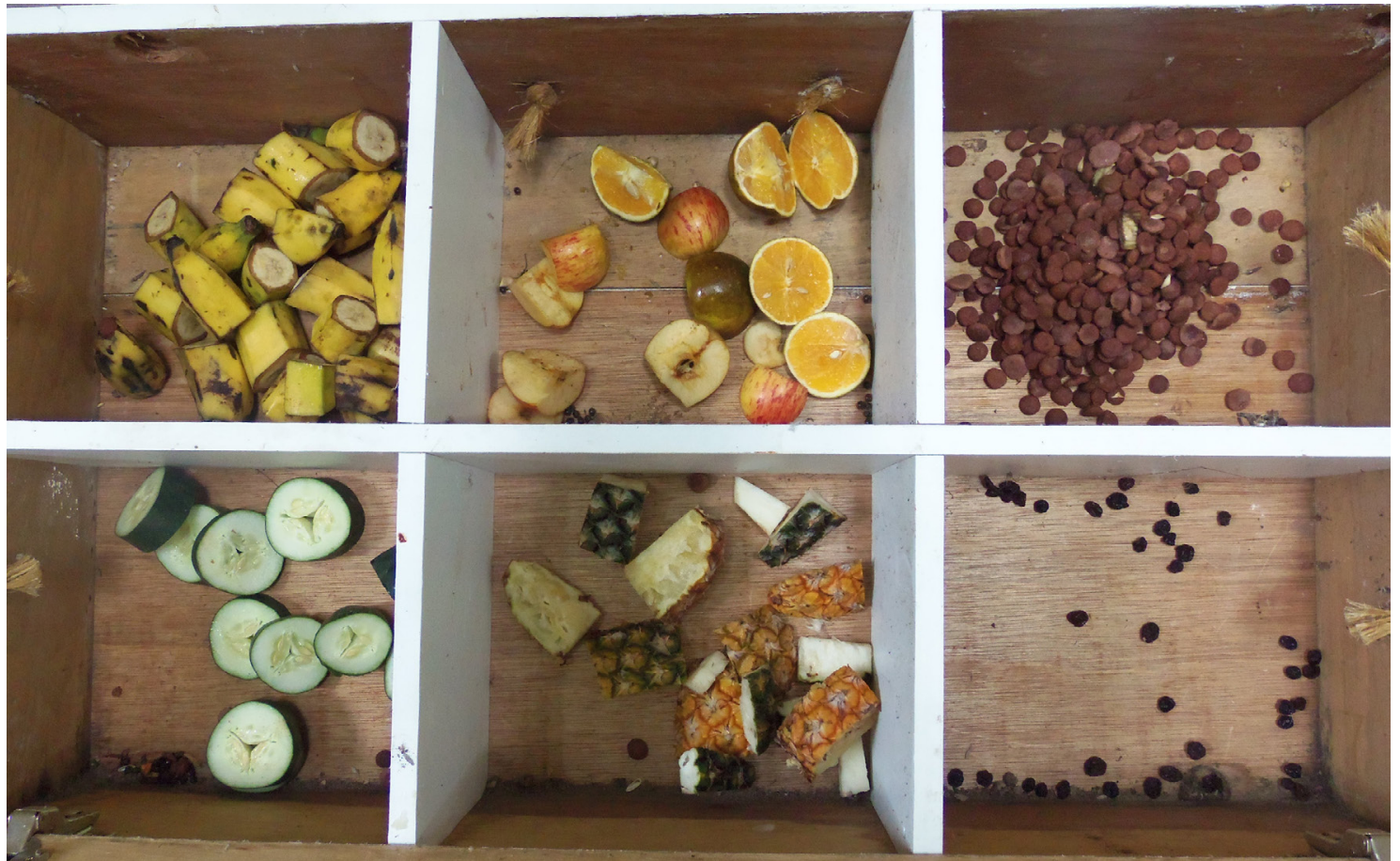

Figura 4. Caixa de competição com itens alimentares separados em compartimentos isolados. 


\section{RESULTADOS E DISCUSSÃO}

\section{Interações sociais de Sapajus flavius em cativeiro}

Foram obtidos 349 comportamentos exibidos pelos animais, sendo $137 \mathrm{sem}$ a presença de visitantes e 212 com a presença de visitantes. As categorias de interação mais frequentes foram "Outros", seguido da categoria "Afiliativas" e "Agonistas" (Fig. 5). As categorias de interações corroboraram com a literatura devido a maior frequência de comportamentos afiliativos e uma baixa quantidade de interações agonísticas (Valença-Montenegro, 2011; Bezerra et al, 2014, Souza, 2014; Ferreira, 2015; Neco, 2015). Entretanto, a categoria outros teve maior destaque que as demais.

As interações com maior amostragem foram: "Vocalização", seguido por "Monopolização", que teve como principal emissor machos-adultos e como receptor o indivíduo jovem e a fêmea-adulta lactante; seguido de "Estereotipia", que não foi exibida pela fêmea-adulta lactante e pelo jovem; e pelo "Agonismo Antrópico". Todas estas interações se agrupam dentro da categoria "Outros". Apenas o comportamento de "Esfregar a Barbela" da categoria "Outros" não ocorreu durante o período de coleta de dados (Fig. 6).

A maior frequência de vocalização corroborou com dados da literatura, ocorrendo também nos momentos iniciais em que a caixa era inserida no recinto, o mesmo ocorreu em uma população in situ quando os animais atingiam a caixa de alimentação (Neco, 2015). Embora, nesse estudo as vocalizações aparentemente tenham sido majoritariamente direcionadas às perturbações fora do recinto dos animais, como barulhos externos, do que propriamente entre indivíduos. Podese levantar a hipótese de que a categoria "Outros" teve maior frequência devido o incremento de comportamentos como estereotipias e agonismo antrópico que constituíram juntos cerca de $25,55 \%$ do total de comportamentos amostrados. A alta frequência de monopolizações pode indicar um aspecto competitivo e de hierarquia, como um grau de dominância dos indivíduos que atuaram como emissor, principalmente machos-adultos, compatível com a literatura da espécie e gênero (Bezerra et al, 2014; Neco, 2015).

O comportamento "Surrupiar" teve como principal emissor o indivíduo jovem que também foi o principal receptor de monopolizações, o que provavelmente pode estar relacionado com uma maior submissão desta classe-etária dentro da população ex situ estudada. Para uma população in situ de macacos-pregos-galegos esse comportamento correspondeu a 6,9\% das interações afiliativas (Neco, 2015), porém se deve considerar a quantidade de indivíduos jovens dentro das populações, sendo apenas um jovem na população ex situ. 


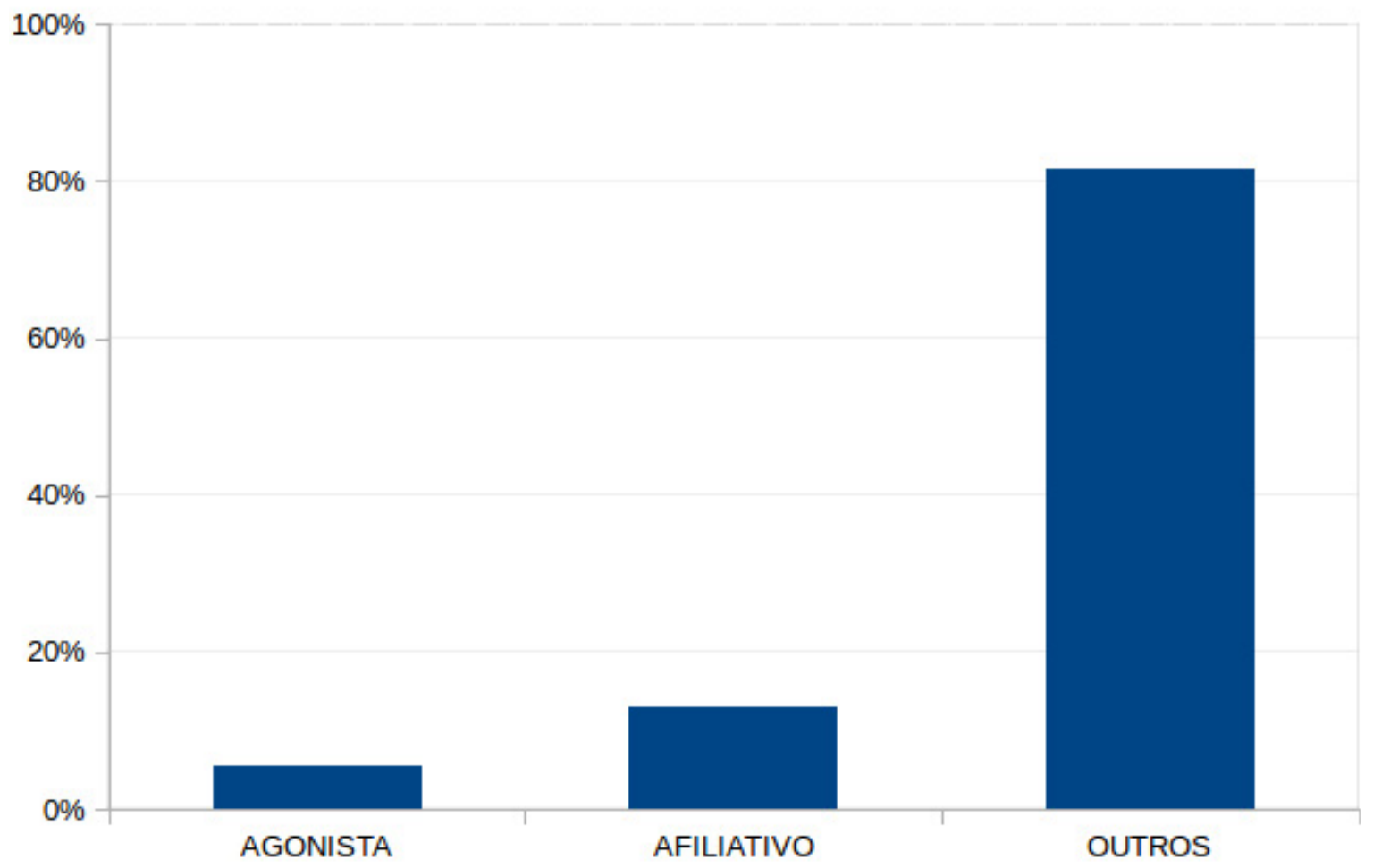

Figura 5. Gráfico do percentual das categorias de interações com e sem visitantes.

O comportamento de esfregar a barbela não foi amostrado no atual estudo, porém teve uma frequência de $12,8 \%$ dentro da categoria outras em um estudo com uma população in situ de $S$. flavius (Neco, 2015). Embora seja desconhecida a função desse comportamento é provável que este deva estar associado a aspectos culturais das populações e pelo isolamento do grupo em cativeiro esse comportamento não tenha sido aprendido pelos indivíduos. Também pode-se levantar a hipótese de que haja um desequilíbrio na estrutura social e até mesmo hormonal dos machos-adultos do grupo, tendo em vista que esse comportamento aparentemente está relacionado com a marcação e a hierarquia dos macacos-pregos-galegos.

A estereotipia ocorreu em todos indivíduos do grupo, exceto a fêmeaadulta progenitora e o jovem, podendo levantar a hipótese de que a atividade de cuidado parental tenha direcionado o gasto energético da fêmea extinguindo os comportamentos estereotipados momentaneamente. Já para o jovem pode-se inferir que possivelmente devido a idade do indivíduo este não tenha adquirido uma quantidade de estresse suficiente para ser convertido em estereotipias.

Outra observação interessante é que de acordo com a diminuição da quantidade de alimento dentro da caixa de alimentos, principalmente os vegetais e frutas, os indivíduos demonstraram uma maior intensidade na frequência de comportamentos estereotipados exibidos. Portanto, a caixa de alimentos aparenta mitigar e auxiliar na diminuição de comportamentos considerados atípicos que ocorrem devido o pouco espaço e da falta de estímulos cognitivos, como a facilidade na captura e consumo de recursos gerando apatia, sedentarismo e problemas psicomotores (Neves, 2018). 
Além disso, sugere-se a inserção de outras técnicas que estimulem atividades cognitivas e gastos energéticos dos macacos-pregos-galegos cativos, como uso de alimentos encapsulados, desafios para obtenção de alimento e um espaço maior e mais arborizado, se possível, com a presença de espécies que façam parte da dieta de S. flavius.

Os comportamentos afiliativos de maior repetição foi "Repousar" realizado majoritariamente pela fêmea-adulta lactante, possivelmente devido o gasto energético despendido durante a gestação, amamentação e parto. Todas as outras interações da categoria foram amostradas como: "Brincar", foi executada por um macho-adulto e um jovem; “Catação”, que foi emitida pela fêmea-adulta progenitora ao infante; "Doação”, que teve como principal receptor o indivíduo jovem; e "Aliança”, que ocorreu apenas duas vezes com dois indivíduos machos-adultos tendo como alvo os visitantes do zoológico (Fig. 6). Nos estudos de Neco (2015), o ato de aliança tem relação estatística significativa com agressões principalmente entre machos, porém no atual estudo esse comportamento foi amostrado apenas uma vez com dois indivíduos machos-adultos compatível com a literatura (Neco, 2015). Mas vale salientar que esse comportamento foi direcionado a presença humana durante a sessão oferta induzida de alimento.

O comportamento de catação teve exclusiva emissão pela fêmea-adulta lactante sendo o receptor exclusivamente o infante, indicando o cuidado parental comum dentro das populações da espécie. Entretanto, nenhuma catação foi direcionada a nenhum outro indivíduo, demonstrando uma ausência desse comportamento para fins sexuais durante o período de amostragem ou uma menor afinidade entre os indivíduos (Fragaszy et al, 2004 apud Neco, 2015). Diferente do estudo in situ e outros estudos ex situ com a espécie e espécies do gênero, os machos receberam maior frequência de catação por jovens e fêmeas, geralmente indicando uma corte para futura cópula (Di Bitetti, 1997; Sena et al, 2013; Ferreira, 2015; Neco, 2015). A doação de alimentos ocorreu principalmente pela emissão de fêmeas e machos-adultos para o jovem, compatível com o estudo macacos-pregos-galegos in situ, onde indivíduos mais velhos, demonstram principalmente uma tolerância na partilha de alimento com indivíduos mais jovens que não conseguem obter seu próprio alimento (Neco, 2015).

A brincadeira social foi amostrada apenas duas vezes emitidas por um indivíduo macho-adulto e um jovem com uma folha que havia dentro do recinto, este comportamento também teve baixa frequência em um estudo in situ da espécie (Neco, 2015). Entretanto, tal comportamento se torna interessante para reduzir o estresse dos animais em cativeiro, tendo em vista a alta capacidade cognitiva do gênero. É fundamental o incremento de técnicas de enriquecimento ambiental e cognitivo que simulem interações ecológicas similares ao ambiente natural dos primatas e que dificultem a aquisição de alimentos. Tais medidas podem auxiliar na diminuição do estresse e da mortalidade do grupo, além de possibilitar uma menor exposição dos espécimes aos seres humanos, esse tipo de manejo ainda pode ser utilizado para a reabilitação de macacos-pregos-galegos resgatados. 
As interações agonísticas, como "Afastar" e "Ameaçar", foram menos frequentes, e direcionadas ao jovem por machos e fêmeas-adultas, possivelmente indicando o fim do cuidado parental rígido durante a partilha de alimento. Os comportamentos de "Agressão" e "Perseguir" não foram amostrados, sendo compatível com pouca violência registrada nos comportamentos da espécie (Valença-Montenegro, 2011; Neco, 2015). Também deve-se levar em conta o tamanho reduzido no grupo de estudo.

A ameaça foi um dos menos frequentes nos indivíduos ex situ. Neco (2015) observou $66,3 \%$ de ameaças numa população natural e com maior direcionamento de machos-adultos para os indivíduos jovens. Porém, nessa pesquisa esse comportamento foi constante entre machos-adultos durante encontros e quando os indivíduos estavam se deslocando pelo recinto e emitindo estereotipias. Possivelmente, esta interação está mais relacionada ao estresse da população cativa do que pela estrutura social do grupo.

A ameaça e a monopolização podem estar relacionados com uma hierarquia por machos-adultos do recinto. A agressão e a perseguição na população in situ eram voltadas para disputas por recursos (Neco, 2015). Entretanto, no zoológico os recursos alimentares são ofertados regularmente para todos os indivíduos e a ausência dos comportamentos de agressão e perseguição podem indicar que os macacos-pregosgalegos não competem por recursos.

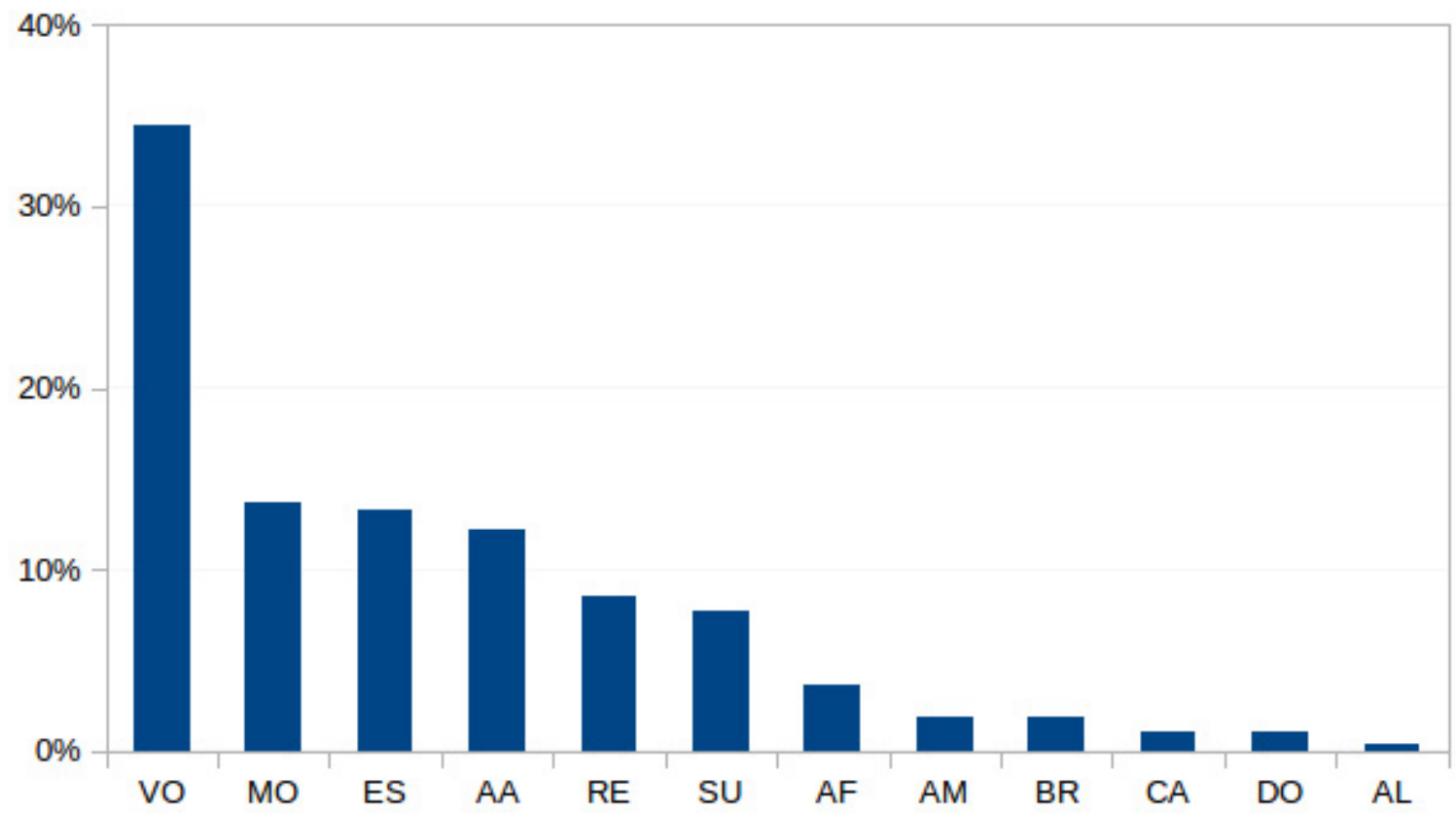

Figura 6. Gráfico de distribuição total de interações dentro de todas as categorias. Afastar (AF); Agredir (AG); Ameaçar (AM); Perseguir (PE); Brincar (BR); Catação (CA); Aliança (AL); Repouso (RE); Doação (DO); Esfregar barbela (EB); Vocalização (VO); Solicitar (ME); Monopolizar (MO); Estereotipia (ES); Agonismo antrópico (AA); Surrupiar (SU). 


\section{Efeitos da presença de humanos no recinto dos macaco-pregos-galegos}

A presença de visitantes no parque diminuiu significativamente as interações "Agonistas" ( $\mathrm{p}<\mathrm{o}$ o. 1) enquanto que a categoria "Outros" ( $\mathrm{p}<\mathrm{o.01}$ ) aumentaram durante o período de visitação do parque (Fig. 7). As interações afiliativas também diminuíram com a presença de visitantes, porém não foi obtida significância estatística (Fig. 7).

Apesar de alguns comportamentos afiliativos mais específicos terem aumentado de frequência, como "Brincar", "Catação" e "Aliança”, essas interações não foram significativas. Já outras interações afiliativas diminuíram com a presença de visitantes como "Repousar" ( $\mathrm{p}$ < 0.05) e "Doação", esta última não apresentou significância (Fig. 8). Já as interações agonísticas de "Ameaça” e "Afastar" sofreram um decréscimo quando o parque recebeu visitantes, essas interações individualizadas não foram significativas (Fig. 8).

A "Vocalização" foi o único comportamento da categoria outros que diminuiu com a presença dos visitantes e apresentou uma significância estatística marginal ( $\mathrm{p}<\mathrm{o.10}$ ). Porém, o oposto ocorreu com "Agonismo Antrópico" aumentou significativamente $(\mathrm{p}<\mathrm{o.01})$ com visitantes no zoológico. $\mathrm{O}$ aumento nas frequência de "Estereotipia” , "Monopolização" e "Surrupiar" nos dias em que os visitantes estavam presentes não apresentou significância estatística (Fig. 8).

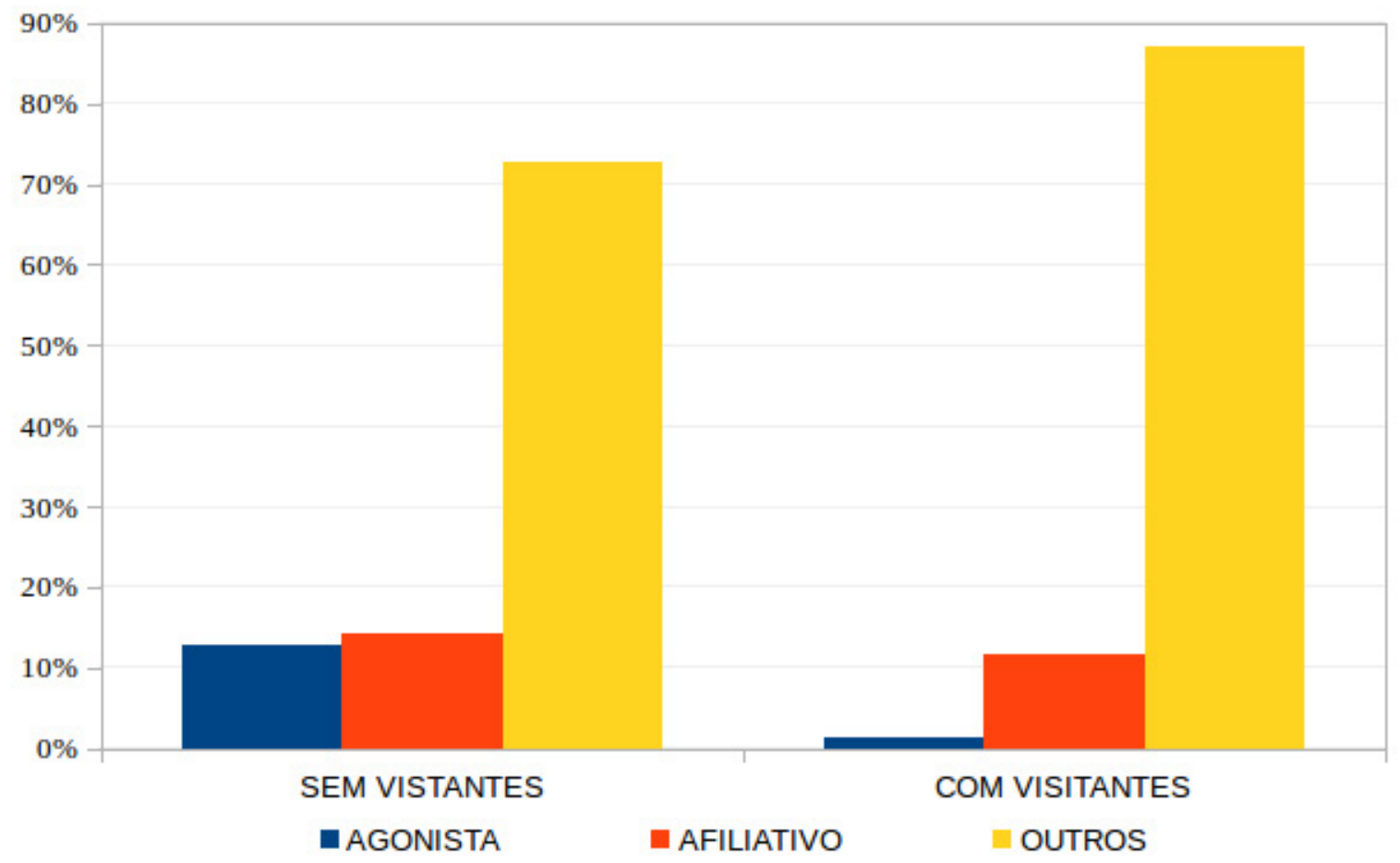

Figura 7. Gráfico de distribuição das categorias de interações sem e com visitantes. 
Os comportamentos afiliativos de "Catação" e "Brincadeiras" também aumentaram quando os visitantes estavam no zoológico. Possivelmente, essas frequências estão associadas a um baixo período de amostragem e também com o oportunismo, tendo em vista que as brincadeiras ocorriam com elementos externos, como uma folha que caiu dentro do recinto e um pepino que foram usados como elementos recreativos pelo indivíduo jovem.

A catação foi direcionada exclusivamente ao filhote que em sessões anteriores não havia nascido. A presença dessa interação durante a presença de visitantes pode estar relacionada com a proteção e cuidado parental da fêmea adulta lactante. Embora "Aliança" seja categorizada como comportamento afiliativo entre os animais, essa interação representa uma associação positiva entre macacos-pregos-galegos que direcionam uma ameaça agonística para outros macacos-pregos-galegos ou outros animais, neste caso os visitantes do parque zoobotânico.A evidente redução dos comportamentos agonísticos durante a presença de visitantes demonstra como a presença humana interfere nas interações sociais entre os animais. Os comportamentos agonísticos podem ser compreendidos como negativos entre os animais pois demonstram algum tipo de agressão ou competição. Porém, essas interações são fundamentais para o estabelecimento da ordem, hierarquias e relações sociais entre as distintas classes etárias e sexos dentro dos grupos de macacos-pregosgalegos. Portanto, os comportamentos agonísticos não são necessariamente danosos aos animais pois são comuns e atribuem estruturas sociais aos indivíduos dentro dos grupos das populações in situ de macacos-pregos-galegos.

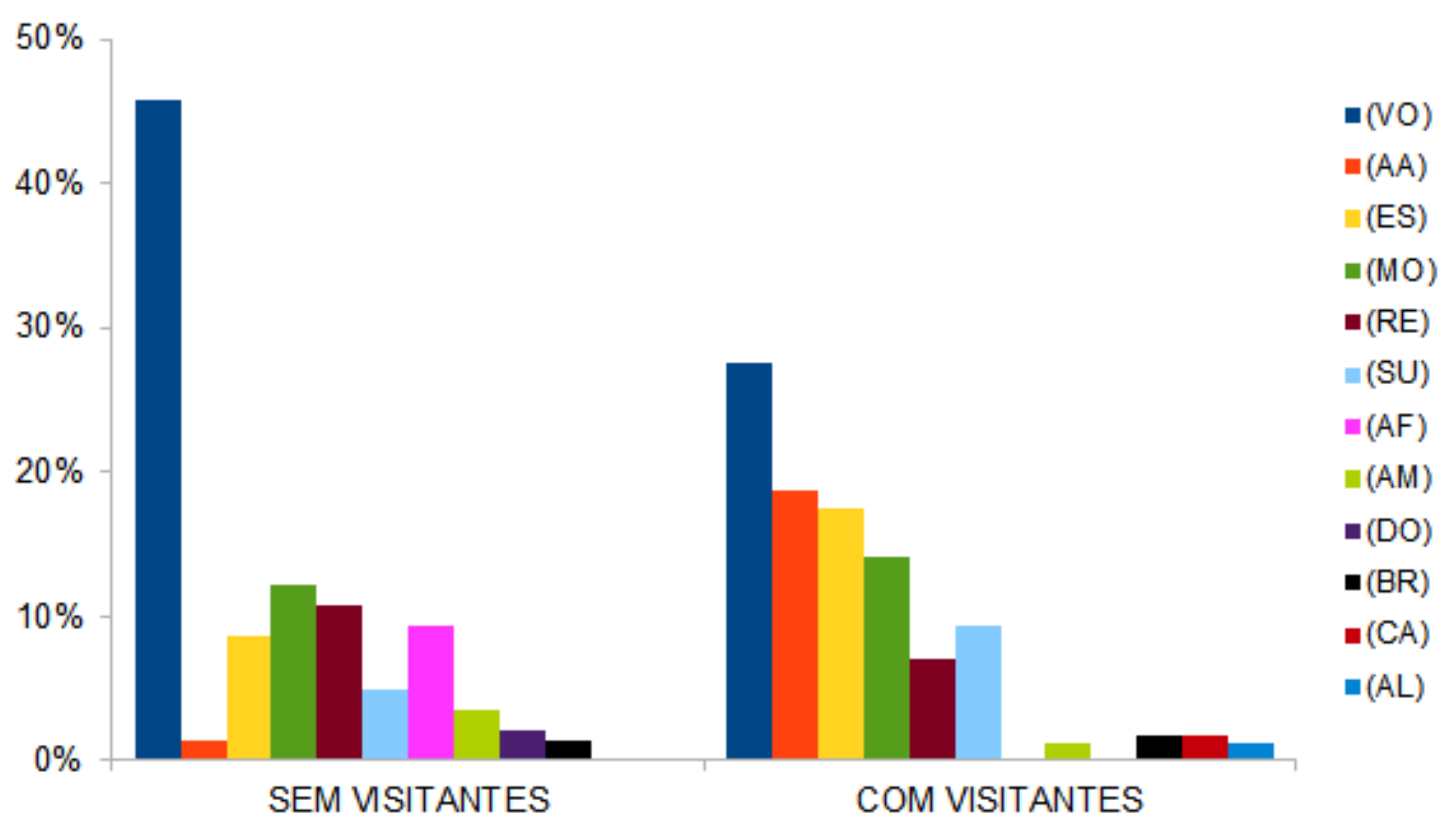

Figura 8. Gráfico de distribuição percentual de todos os comportamentos sem e com visitantes. Afastar (AF); Agredir (AG); Ameaçar (AM); Perseguir (PE); Brincar (BR); Catação (CA); Aliança (AL); Repouso (RE); Doação (DO); Esfregar barbela (EB); Vocalização (VO); Solicitar (ME); Monopolizar (MO); Estereotipia (ES); Agonismo antrópico (AA); Surrupiar (SU). 
A interferência gerada pela presença humana demonstrou significância principalmente para uma diminuição dos comportamentos agonistas e para o aumento das interações da categoria outros, como agonismo antrópico. Com a presença dos visitantes o agonismo antrópico aumentou $17,28 \%$ sua frequência, possivelmente isto deve ter ocorrido devido o estresse e a energia dos comportamentos agonísticos e afiliativos dos animais cativos terem sidos redirecionados para os visitantes do que para os macacos-pregos-galegos do recinto. Essa mesma hipótese provavelmente está relacionada com a diminuição significativa da ocorrência das vocalizações durante a presença de visitantes. Os visitantes demonstraram desconhecer ou não respeitar as instruções do parque zoobotânico sobre os impactos, perturbações e consequências causadas ao incomodar os animais.

Embora, a entrada de visitantes seja vetada em determinados dias no parque é evidente a presença contínua de seres humanos próximos no recinto, tanto pesquisadores e funcionários quanto transeuntes que utilizam o parque como passagem para chegarem aos seus destinos. Além disso, deve-se levar em consideração o estresse causado pela redução da área de vida dos animais a poucos metros cúbicos do recinto, as populações selvagens de $S$. flavius utilizam entre 80 e 187 ha diariamente. Mesmo esse local sendo enriquecido ambientalmente ele aparenta não suprir as necessidade energéticas e ecológicas dos macacos-pregosgalegos (Valença-Montenegro, 2011; Valença-Montenegro et al, 2015; Neves, 2018).

Segundo Fragaszy e colaboradores (2004), as fêmeas de S. flavius atingem a maturidade sexual com 4 a 5 anos de vida, enquanto que os machos atingem a maturidade sexual com 7 anos. Além disso, o intervalo entre gestações de $S$. flavius demora entorno de 19 a 24 meses sendo produzido, geralmente, apenas um filhote por gestação. Os macacos-pregos-galegos podem atingir entre 40 e 50 anos em cativeiro, porém geralmente os indivíduos do zoológico demonstram ter uma longevidade menor que isso. Alguns infantes e adultos já foram encontrados mortos com idades menores que as indicadas na literatura (Fragaszy et al, 2004; Valença-Montenegro, 2011; Valença-Montenegro et al, 2015).

Portanto, a interferência humana pode prejudicar os macacos-pregosgalegos cativos, tendo em vista que o estresse pode interferir no bem estar e nas relações sociais de $S$. flavius, o impacto humano pode comprometer a conservação e preservação da espécie, como também a manutenção a curto e longo prazo dos macacos-pregos-galegos cativos.

\section{CONSIDERAÇÕES FINAIS}

De acordo com as informações obtidas no presente estudo pode-se observar alterações nas interações sociais de $S$. flavius cativos quando comparadas à população in situ, principalmente por comportamentos provocados pelo acúmulo de estresse. Durante o período aberto aos visitantes o grupo ex situ aumentou significativamente 
o agonismo antrópico e diminuiu o repouso e as interações agonísticas em detrimento do aumento das interações da categoria outros. Uma observação interessante é que o comportamento "Esfregar Barbela" não foi amostrado durante a pesquisa, podendo indicar um aspecto cultural sobre tal interação, cuja a função ainda é desconhecida.

Portanto, recomenda-se maiores atividades de educação ambiental para os demais frequentadores do parque, seja pesquisadores, funcionário ou visitantes, com a intenção de diminuir o estresse provocado aos macacos-pregos-galegos cativos. A incrementação de técnicas de enriquecimento ambiental e cognitivo e, possivelmente, alteração da localização do recinto englobando uma área arborizada para abrigo e para proporcionar relações ecológicas mais próximas às naturais. Para a dieta dos animais pode-se sugerir o uso de espécie vegetais endêmicas e de espécies presentes tanto na dieta quanto no ambiente natural de $S$. flavius.

\section{AGRADECIMENTOS}

Ao Gustavo Vilar por viabilizar e auxiliar na logística da pesquisa e pelos seus conhecimentos sobre comportamento animal. A tratadora Lilian e o tratador Cícero por permitirem intrusos em sua rotina de trabalho e por nos recepcionaram calorosamente, assim como os demais funcionários do Parque Arruda Câmara. Por último e não menos importante aos macacos-pregos-galegos cativos e de vida livre.

\section{REFERÊNCIAS}

ALTMANN, Jeanne. 1974. Observational study of behavior: sampling methods. Behaviour, v. 49, n. 3, p. 227-266.

BEZERRA, B. M.; BASTOS, M.; SOUTO, A.; KEASEY, M. P.; EASON, P.; SCHIEL, N.; JONES, G. 2014 Camera trap observations of nonhabituated critically endangered wild blonde capuchins, Sapajus flavius (Formerly Cebus flavius). International Journal of Primatology, 35 (5): 895-907.

DI BITETTI, M.S. 1997. Evidence for na important social role of allgrooming in a platyrrhine primate. Anim Behavi 54: 199-211.

FERREIRA, R. S. 2015.Dinâmica na estrutura social de Sapajus flavius cativos

no Parque Estadual de Dois Irmãos, Recife, PE. Trabalho de Conclusão de Curso (Graduação em Ciências Ambientais) - Universidade Federal de Pernambuco, Recife. 
FRAGASZY, D.M.; VISALBERGHI, E.; FEDIGAN, L.M. 2004. The Complete Capuchin: The Biology of the Genus Cebus. Cambridge: Cambridge University Press. v.1. 1 ed. p 349.ISBN-13: 978-0521667685.

HARE, V. J. 20oo.Environmental Enrichment Advancing Animal Care. Universities Federation for Animal Welfare. $1^{\mathrm{a}}$ ed. 240 p. ISBN-13: 978-0632064076.

IZAR, P. et al. 2009. Sexual selection, female choice and mating systems. South American Primates. New York: Springer.p. 157-189.

JACOBSEN, K. R.; MIKKELSEN, L. F.; HAU, J. 2010. The effect of environmental enrichment on the behavior of captive tufted capuchin monkeys (Cebus apella). Lab animal, v. 39, n. 9, p. 269-277.

JANSON, C. H. 1985. Aggressive competition and individual food consumption in wild brown capuchin monkeys (Cebus paella). Behav. Ecol. Sociobiol.18 (2): 125-138.

LUDWIG, G; AGUIAR, L. M; ROCHA, V.J. 2005.Uma Avaliação da Dieta, da área da vida livre e das estimativas populacionais de Cebus nigritus (Goldfuss, 1809) em um fragmento florestal no norte do estado do Paraná. Neotropical Primates, Belo Horizonte, v. 13, n. 3, p. $12-18$.

MASON, G.; CLUBB, R.; LATHAM, N.; VICKERY, S. 2007. Why and how should we use environmental enrichment to tackle stereotypic behaviour. Applied Animal Behaviour Science, v. 102, p. 163-188.

MMA. Ministério do Meio Ambiente. Portaria $N^{\circ}$ 444. 2014. Reconhece como espécies da fauna brasileira ameaçadas de extinção aquelas constantes da “Lista Nacional Oficial de Espécies da Fauna Ameaçadas de Extinção”.

NECO, E. C. 2015. Interações sociais em um grupo de macaco-prego-galego Sapajus flavius (Schreber, 1774) sob competição induzida por alimento, em área de Floresta Atlântica na Paraíba. Paraíba, Brasil. Dissertação - Universidade Federal da Paraíba.

NEVES, I. M. 2018. Perfis comportamentais e estrutura da rede social de uma colônia cativa de Sapajus flavius (Primata ameaçado de extinção), visando sua conservação. 52 f. Monografia Bacharel em Ciências Biológicas. Universidade Federal Rural de Pernambuco, Recife.

OLIVEIRA, M.M., BOUBLI, J.-P. \& KIERULFF, M.C.M. Sapajus flavius. The IUCN Red List of Threatened Species. 2015: Disponível em: <"http://dx.doi.org/10.2305/IUCN. UK.2015.RLTS.T136253A70612549.en”>. Acesso em maio de 2019. 
PINHA, P. S. 2007. Interações sociais em um grupo de macacos-prego (Cebus libidinosus) no Parque Nacional de Brasília. Dissertação (Mestrado em Ecologia) - Universidade Federal de Brasília, Brasília.

R CORE TEAM (2019). R: A language and environment for statistical computing. $\mathrm{R}$ Foundation for Statistical Computing, Vienna, Austria. Disponível em:<"https:// www.R-project.org/"> Acesso em maio de 2019.

RODRIGUES, K. C. 2013a.Padrão de atividades, comportamento alimentar, exploração de habitat eárea de vida de um grupo de Sapajus flavius (Schreber, 1774) (Primates, Cebidae) em um fragmento de floresta atlântica, Paraíba, Brasil. 58 p. Dissertação (Mestrado em Ecologia e Monitoramento Ambiental) Universidade Federal da Paraíba, João Pessoa.

RODRIGUES, K. C.; DELFIM, F. R.; CASTRO, C. S. S.; FRANCA, F. G. R.; LEITE FILHO, E.; MESQUITA, D. O.; OLIVEIRA, F. A.; SANTOS, A.C.A.; FERRARI, S. F.; VALENÇA-MONTENEGRO, M. M. 2013b. Strobilurus torquatus Wiegmann, 1834 (Squamata:Tropiduridae): New records from the Brazilian State of Paraíba and a geographic distribution map. Check List, v. 9, p. 614- 617.

SAATCHI, S. et al. 2001. Examining fragmentation and loss of primary forest in the southern Bahian Atlantic forest of Brazil with radar imagery. Conservation Biology, v. 15 , n. 4 , p. $867-875$.

SANTOS, A.C.A. 2010. Atividades antrópicas que ameaçam o macaco-pregogalego Cebus flavius (Schreber, 1774) em um fragmento de Mata Atlântica na Paraíba. 22 p. Monografia (Bacharelado em Ciências Biológicas) - Universidade Estadual da Paraíba, João Pessoa.

SANTOS, A. C. A. 2013.Padrão de forrageamento de Cebus flavius (Schreber, 1774) (Primates: Cebidae), em um fragmento de Mata Atlântica na Paraíba. 77p. Dissertação (Mestrado em Ecologia e Conservação) Universidade Federal de Sergipe, São Cristóvão.

SUSCKE, P. 2009.Padrão de atividades, dieta e uso do espaço de um grupo de Cebus xanthosternos (Wied-Neuwied, 1820) (Primates, Cebidae) na Reserva Biológica de Una, Bahia, Brasil. Tese de Doutorado. Msc Dissertation. Universidade Estadual de Santa Cruz, Bahia.

SENA, M. V. A.; PESSOA, A. R.; OLIVEIRA, W. F. L.; CAMELO, D. M. M.; SILVA, E. G.; MELO, L. C. O.; BANDEIRA, R. L.; SANTINO, M. B.; CANUTO, S. M.; MONTEIRO DA CRUZ, M. A. O. 2013. Interações no grupo de macacos-prego-galegos (Sapajus 
flavius) do Parque Estadual Dois Irmãos, Recife - PE. In: II Congresso Latino Americano XV Congresso Brasileiro de Primatologia, Recife. Anais, p. 235.

SILVA, G. A. O.; VALENÇA-MONTENEGRO, M.M. 2016. Ecologia Alimentar e Nutricional de Sapajus flavius como Critério de Escolha de Áreas para Reintrodução da Espécie, Contribuição: Estação Experimental de Camaratuba. In: VIII Seminário de Pesquisa e Iniciação Científica do Instituto Chico Mendes de Conservação da Biodiversidade. Brasília. 1 CD-ROOM.

STRIER, K. B. 2003.Primate behavioral ecology: from ethnography to ethology and back. American Anthropologist, v. 105, n. 1, p. 16-27.

TRIBE, A.; BOOTH, R. 2003. Assessing the role of zoos in wildlife conservation. Human Dimensions of Wildlife, v. 8, n. 1, p. 65-74.

VALENÇA-MONTENEGRO, M.M. 2011. Ecologia de Cebus flavius (Schreber, 1774) em remanescentes de Mata Atlântica no estado da Paraíba. Tese (Doutorado) - Escola Superior de Agricultura "Luiz de Queiroz". Centro de Energia Nuclear na Agricultura, Piracicaba.

VALENÇA-MONTENEGRO, M.M.; BEZERRA, B.M.; MARTINS, A.B.; FIALHO, M.S. 2015a. Avaliação do Risco de Extinção de Sapajus flavius (Schreber, 1774) no Brasil. Processo de avaliação do risco de extinção da fauna brasileira. ICMBio. Disponível em:<"http://www.icmbio.gov.br/portal/faunabrasileira/estado-deconservacao/7272-mamiferos-sapajus-flavius-macaco-prego-galego">. Acesso em maio de 2019. 